\title{
Ameaçada, comunicação pública é vital para a democracia
}

\author{
Threatened, the public communication is vital to democracy \\ Amenazada, la comunicación pública es vital para la democracia
}

\author{
Laurindo Lalo Leal Filho | laloleal@uol.com.br \\ TV Brasil. São Paulo, SP, Brasil.
}

\section{Resumo}

Diante das ameaças de retrocessos políticos e sociais no país, que incluem o desmonte da TV Brasil e da Empresa Brasil de Comunicação (EBC), esta nota discute a importância da comunicação pública para as sociedades democráticas. A análise parte de referências históricas, conceituais, e da relação entre Estado e comunicação. Aborda a relação intrínseca entre comunicação pública e o direito à comunicação e sua centralidade nas instituições estatais de caráter público. A partir do modelo de comunicação pública desenvolvido na Europa ocidental, situa a criação da EBC como marco histórico da comunicação pública no país, e apresenta exemplos de sua trajetória recente que expressam sua maior integração com a sociedade.

Palavras-chave: comunicação pública; televisão pública; TV Brasil; EBC; direito à comunicação.

\begin{abstract}
Given the threats of political and social retrogressions in Brazil, including the policy of dismantling the TV Brasil and the Empresa Brasil de Comunicação (EBC), this note discusses how is important the public communication to democratic societies. Historical and conceptual references as well as the relations between the state and communication are the starting point for the analysis. It deals with the inherent relation between public communication and the communication rights and its centrality in the public nature of governmental institutions. Based on the model of public communication developed in Western Europe, this note shows that EBC represents a milestone in the Brazilian public communication history and gives examples of its recent trajectory indicating that it was more and more integrated into national society.
\end{abstract}

Keywords: public communication; public TV; TV Brasil; EBC; communication right.

\section{Resumen}

Frente a las amenazas de los retrocesos políticos en el país, que incluyen el desmantelamiento de la TV Brasil y de la Empresa Brasil de Comunicação (EBC), esta nota examina la importancia de la comunicación pública para las sociedades democráticas. El análisis parte de referencias históricas, conceptuales y de la relación entre Estado y comunicación. Trata de la relación intrínseca entre comunicación pública y el derecho a la comunicación y su centralidad en las instituciones estatales de carácter público. A partir del modelo de comunicación pública desarrollado en Europa Occidental, establece la creación de la EBC como marco histórico de la comunicación pública en lo país y presenta ejemplo de su trayectoria reciente que expresan su mayor integración con la sociedad.

Palabras clave: comunicación pública; televisión pública; TV Brasil; EBC; derecho a la comunicación. 
Contribuição dos autores: o autor é responsável por todo o texto

Declaração de conflito de interesses: nenhum

Fontes de financiamentos: não houve

Considerações éticas: nada a declarar

Agradecimento/Contribuições adicionais: nada a declarar

Histórico do artigo: Submetido: 09.ago.2016 | Aceito: 20.set.2016 | Publicado: 30.set.2016.

Apresentação anterior: Esta nota é uma atualização de palestra realizada na Universidade Estadual de Campina Grande, Paraíba, em 03/06/2016.

Licença CC BY-NC atribuição não comercial. Com essa licença é permitido acessar, baixar (download), copiar, imprimir, compartilhar, reutilizar e distribuir os artigos, desde que para uso não comercial e com a citação da fonte, conferindo os devidos créditos de autoria e menção à Reciis. Nesses casos, nenhuma permissão é necessária por parte dos autores ou dos editores.

Vivemos momentos inéditos na vida do país onde retrocessos políticos e sociais inimagináveis estão acontecendo ao lado de um despertar da cidadania também pouco visto na história do Brasil com seu enraizamento nas bases da sociedade e por sua abrangência nacional.

Na televisão pública assiste-se não apenas ao desmonte da TV Brasil, mas de toda a Empresa Brasil de Comunicação (EBC), criada há menos de dez anos e que pretendia colocar o nosso pais num patamar próximo ao das grandes democracias do mundo, onde as emissoras públicas têm histórias que remontam a quase cem anos. Por aqui até que começamos bem com Roquette Pinto criando a Radio Sociedade do Rio de Janeiro, hoje Rádio MEC (vinculada à EBC) nos mesmos moldes da BBC de Londres. Só que lá a emissora continua pública até hoje. Aqui, a nossa emissora pública foi engolida pelos interesses comerciais que - como todos sabemos - controla a comunicação no Brasil a partir de seus interesses políticos e mercadológicos.

Só se voltou a falar em comunicação pública de abrangência nacional com os Fóruns Nacionais sobre o tema impulsionados pelo governo federal em 2007, que resultaram na criação da EBC com suas duas emissoras de televisão, oito de rádio, duas agências de notícias e uma área de prestação de serviços externos. Ainda que muito distante em termos de recursos e de abrangência de sinal, as emissoras da EBC passaram a incomodar a mídia hegemônica ciosa de sua exclusividade para ditar o que o brasileiro e a brasileira devem saber e pensar. Ao mostrar que outra mídia é possível, diferentemente do que veicula a mídia tradicional, a comunicação pública passou a incomodar. A resposta inicialmente foi a chacota - "TV do Lula", "TV traço" e por aí afora - mas depois, com o golpe de Estado, passou-se à sua destruição, pura e simples.

Esse é o quadro atual. Vamos a algumas referências históricas e conceituais. A comunicação pública situa-se no terreno de disputa entre a defesa de um Estado mínimo, garantidor apenas do funcionamento estável do mercado, ou de um Estado democrático com forte presença na regulação econômica e no ordenamento social, nos moldes do Estado de bem-estar social como os fundados na Europa no pós-guerra.

É importante deixar isso claro já que não é possível discutir o papel de qualquer variante da comunicação social sem entender em que tipo de Estado ela está inserida. Em se tratando de comunicação pública a questão é mais aguda já que quase sempre, em última instância, ela depende de algum tipo de impulso dos gestores governamentais do Estado. Se a opção for pelo Estado mínimo, ela está condenada ao desaparecimento ou na melhor das hipóteses a um papel residual, muitas vezes apenas para dar conta de dispositivos legais, transformando-se em porta-voz governamental. Se a saúde, a educação e a previdência, 
entre outras políticas públicas, são desprezíveis nesse tipo de Estado, o que esperar de uma possível atenção à comunicação pública?

E mais. Historicamente cabe a pergunta: “como fazer TV pública num pais semiescravocrata?” Num pais onde o coronelismo rural adaptou-se ao meio urbano transformando-se no coronelismo eletrônico, indispensável para a manutenção do poder político nas mesmas mãos, sempre.

A TV pública é uma ameaça a esse poder. No Brasil, ela é uma "ideia fora do lugar" num feliz achado da pesquisadora Ângela Carrato que, em seu doutorado sobre a TV pública brasileira, relacionou essa ideia com a mesma expressão - "ideia fora do lugar" - formulada por Roberto Schwarz a respeito do liberalismo no Brasil'

A TV pública impulsionada pelo Estado vai na contra-mão dos interesses dominantes que, sob o véu do liberalismo, julgam-se no direito absoluto de impor à sociedade suas ideias, gostos, valores, sem nenhum tipo de controle. A TV pública é uma forma de controle social da mídia. Dai a violência com que é atacada.

Dito isso, cabe discutir esse tipo de comunicação nos limites de uma política de Estado de amplo espectro social, compromissada com a observância dos direitos humanos fundamentais, neles incluídos o direito à comunicação ${ }^{2}$, do qual a comunicação pública é parte estruturante. É em torno de sua centralidade que se desenvolvem as instituições estatais de caráter público, as empresas privadas prestadoras de serviços públicos e as emissoras sem fins comerciais, voltadas para o atendimento de demandas comunitárias.

No Brasil, a história da comunicação pública é incipiente. Em 2007, tive a oportunidade de apresentar um trabalho ${ }^{3}$ na reunião da Associação Nacional dos Programas de Pós-Graduação em Comunicação (Compós), realizada em Curitiba, onde falava de nosso "vazio histórico" nessa área. Lembrei as origens de nossa radiodifusão, de caráter público, mas em pouco tempo ofuscado pela ascensão e hegemonia do modelo comercial.

De 2007 para cá, quando mencionei o "vazio histórico" a situação mudou - mas não muito. O marco mais importante nesse período recente foi a consolidação da Empresa Brasil de Comunicação (EBC), ampliando o debate em torno da comunicação pública no país. As vozes contrárias, amplificadas pela mídia comercial serviram, ainda que pelo viés negativo, para revelar a possibilidade da existência de um outro modelo de comunicação, consagrado na Europa ocidental mas praticamente desconhecido no Brasil.

No entanto, se a criação da EBC deu alento ao debate sobre o modelo público de comunicação, a sua concretização prática ainda se ressente de uma realização plena. O não atendimento a dois princípios básicos para a sua existência e funcionamento exemplificam esta afirmação. São eles: a universalidade geográfica ${ }^{4}$ a ética da abrangência ${ }^{5}$.

A universalidade geográfica refere-se à possibilidade de acesso de toda a população ao serviço público de radiodifusão, condição básica para justificar a existência do sistema. Entendido como direito humano, esse tipo de comunicação deve ser garantido a todos, como se faz, ou deveria se fazer, com a saúde e a educação, por exemplo. Vista como serviço, deve ser oferecida de forma igual e sem nenhum tipo de discriminação a toda a sociedade que o mantém. É importante frisar que a comunicação é um serviço e um direito ao mesmo tempo.

No caso brasileiro esses requisitos ainda não são atendidos. O acesso aos sinais das emissoras públicas de rádio e televisão ainda é parcial, com amplas áreas de sombra por onde elas não trafegam. Com isso, formam-se dois tipos de cidadãos: aqueles que podem usufruir de um sistema público de comunicação e os que dele são alijados.

O segundo princípio, a ética da abrangência, trata do atendimento pelo sistema público das necessidades simbólicas de toda a população, através de uma programação capaz de satisfazer o mais amplo espectro de gostos e interesses existentes na sociedade.

Com a digitalização esse objetivo torna-se menos difícil. A TV pública para dar conta dos interesses e gostos da maioria da população precisa operar pelo menos quatro canais de TV: um generalista, outro de notícias 24 horas, um infantil e mais um de cinema e artes em geral. 
$\mathrm{O}$ atendimento às necessidades simbólicas da população não exclui naturalmente dos produtores o desafio de ousar, levando ao público temas e propostas inovadoras capazes de ampliar os horizontes do conhecimento e da imaginação. As emissoras públicas têm a obrigação de "despertar o público para ideias e gostos culturais menos familiares, ampliando mentes e horizontes, e talvez desafiando suposições existentes acerca da vida, da moralidade, da sociedade. A televisão pode também elevar a qualidade de vida do telespectador, em vez de meramente puxá-lo para o rotineiro"5.

Limitações tecnológicas dificultaram durante muito tempo a possibilidade plena de atingir essa meta. No modelo analógico de rádio e televisão, os sistemas públicos consagrados internacionalmente optaram primeiro por constituir emissoras com programações generalistas procurando, numa única frequência, atender aos gostos dos públicos mais diversos. Posteriormente, criando emissoras alternativas para atender interesses mais específicos, os canais voltados para públicos segmentados. Exemplo clássico é a $\mathrm{BBC} 2$, no Reino Unido.

A comunicação no Brasil, salvo raras exceções, sempre foi operada como um instrumento a serviço de interesses políticos ou econômicos, ambos na maioria das vezes concentrados no mesmo grupo empresarial e nos veículos por ele controlados. Cristalizou-se no país a ideia de que a comunicação é um negócio como outro qualquer, obscurecendo no imaginário da sociedade a possibilidade da existência de alternativas.

O monopólio comercial da comunicação, construído ao longo de quase um século mantém-se intacto. Para rompê-lo existem dois caminhos: uma lei que redefina o uso do espaço eletromagnético por onde trafegam as ondas do rádio e da TV, tornando-o equilibrado entre as emissões públicas, privadas e privadas sem fins lucrativos (as comunitárias) e o fortalecimento da comunicação pública com potencial capaz de se tornar alternativa de fato ao modelo hegemônico, tanto de ponto de vista técnico como de conteúdo.

Aqui tratamos apenas do segundo caminho. Para trilhá-lo é necessária uma articulação que combine vontade e decisão política com a absorção e a aplicação do que se convencionou chamar de convergência midiática. Cabe ao Estado impulsionar esse processo que não nasce de geração espontânea e nem vive acima das disputas em torno da hegemonia política, por sobre os interesses de classe. Quem o impulsiona é o Estado, que detém a titularidade sobre os meios públicos de comunicação. Seu caráter público, como de qualquer ente estatal, se dá através da transparência da gestão. No caso da radiodifusão, os veículos serão mais ou menos públicos de acordo com os mecanismos existentes no seu interior que garantam de alguma forma a participação da sociedade em suas linhas gerais de orientação e administração. Exercem esse papel conselhos curadores, audiências públicas, ouvidorias, grupos de assessoramento, sociedades de ouvintes e telespectadores, entre outros.

Hoje, a comunicação pública não pode mais ser vista e pensada em torno de veículos isolados como o rádio, a TV e a internet. A complementaridade entre eles é fundamental. A consagrada "sociedade em rede" no caso da comunicação pública não deve se restringir, por exemplo, à internet. A rede deve incluir os vários tipos de emissoras de rádio e TVs não comerciais existentes de forma ainda desarticulada pelo país. Só assim constituirão uma massa crítica com capacidade para se apresentar como alternativa aos meios comerciais deixando de ser, como muitas vezes são referidos, apenas complementares ao grupo hegemônicoi.

Devem, ao contrário, estabelecer padrões de qualidade capazes de se transformar em paradigmas a serem seguidos pelas demais emissoras. Nesse sentido, além de oferecer um serviço qualificado ao público, a comunicação pública tem também a responsabilidade pedagógica de torná-lo capaz de exigir a mesma qualidade das emissoras comerciais.

\footnotetext{
i A referência ao "princípio da complementariedade dos sistemas privado, público e estatal" constante do artigo 223 da Constituição Federal leva muitas vezes ao engano, intencional ou não, de tratar a comunicação pública como "complementar" às demais, no sentido subalterno de atuar nos espaços pelos quais as outras, particularmente a privada, não se interessam. A acepção correta do termo remete a uma complementariedade equilibrada em que os três modelos devem se equivaler, tanto em tamanho, como em abrangência de sinais.
} 
Para tanto é fundamental a busca da audiência, não para atender ao mercado publicitário, como fazem as emissoras comerciais, mas para qualificar e expandir o debate público tanto relativo à informação como ao entretenimento. Tal patamar só será atingido se a comunicação pública estiver dotada, além de uma produção de qualidade, de sinais de frequência fortes e acessíveis em qualquer ponto do país. Exemplificando com a televisão: seu sinal analógico ou digital deve estar à disposição do público, no dial, junto aos das redes comerciais, podendo ser sintonizado com facilidade.

Na história da televisão brasileira há um momento simbólico em que esse processo pode ser visto na prática. Foi quando a TV Cultura de São Paulo, no início da década de 1990, colocou no ar uma grade de programação infantil com programas que se tornaram referência de qualidade no Brasil e no exterior, como Rá-tim-bum, Mundo da Lua, Bambalalão, entre outros. Transmitida no final da tarde, conquistou a maior audiência da história da emissora, nunca mais alcançada, incomodando as empresas comerciais. O SBT, por exemplo, reformulou sua programação naquele horário, contratando profissionais da própria Cultura para fazer frente à concorrência. Naquele momento, a TV pública prestava um duplo serviço à sociedade: oferecia bons produtos ao seu público e contribuía para elevar a qualidade do que era oferecido pelas emissoras comerciais.

É nesse quadro institucional que devem ser entendidas as práticas e as diretrizes para a produção cultural nas TVs públicas. Ela só será autêntica e abrangente se for gerada a partir de foros democráticos capazes de dar conta da diversidade cultural existente na sociedade. Executivos, diretores de programas, produtores, apresentadores não podem abrir mão de suas competências profissionais na criação de programas e programações, mas não podem também trabalhar isoladamente sem o escrutínio constante de outras vozes e opiniões. Daí a importância da existência de Conselhos Curadores, amplamente representativos da sociedade, capazes de trazer para a produção midiática vozes, anseios e realizações existentes no conjunto da população, capazes de transitar pelos meios de comunicação públicos.

Para não ficar apenas na teorização, dou exemplos concretos desse movimento existente na EBC. Integravam o Conselho da empresa pessoas residentes nas diversas regiões do país, vinculadas ou não a entidades ou movimentos sociais, mas grande parte tendo alguma relação com a luta da mulheres, dos negros, dos movimentos LGBT, dos índios, dos deficientes e assim por diante. São essas pessoas que trazem para as emissoras o pulsar da sociedade que de alguma forma acaba aparecendo nas programações de rádio e televisão da EBC.

Dessa forma, a produção cultural brasileira ganhou espaços impossíveis de serem alcançados dentro dos limites do mercado, imposto à mídia comercial. Graças à autonomia de gestão e ao controle da sociedade tornou-se possível a exibição de programas que discutem o próprio fazer televisivo no país, como é o caso do VerTVii que, há dez anos, discute temas que são tabu nas emissoras comerciais. Fala da questão das concessões de rádio e TV, por exemplo, tema guardado a sete chaves pelas emissoras privadas. Ou da exploração do corpo da mulher nos comerciais, da propaganda criminosa dirigida às crianças, dos programas brutalizadores da sociedade denominados policialescos que diariamente - em todo o Brasil violam direitos consagrados na Constituição brasileira, nas leis do país, nos acordos internacionais e nos códigos de ética como bem revelou pesquisa recente da Andi - Comunicação e Direitosiii.

Coube à TV Brasil, mais recentemente, colocar no ar o primeiro programa LGBT da televisão brasileira, mostrando com seriedade e respeito um mundo excluído ou ridicularizado nas telas de TV. Personagens da vida pública brasileira, com algum compromisso de luta social mais ampla, são personas não gratas na TV comercial. Na TV Brasil eles podem se expressar livremente confrontando suas ideias e pontos de vista com os mais conservadores.

ii Disponível em: http://tvbrasil.ebc.com.br/vertv.

iii Disponível em: http://www.andi.org.br/publicacao/pesquisa-detecta-numero-surpreendente-de-violacoes-de-direitos-e-infracoes-leis-em. 
No entretenimento, é a TV pública que escapa das amarras da audiência a qualquer preço e pode mostrar ao Brasil o que o país faz na música, na dramaturgia, no cinema, no humor e por que não no jornalismo. $\mathrm{O}$ samba, por exemplo, na televisão comercial aberta, reduz-se ao programa Samba na Gamboa ${ }^{\text {iv }}$, da TV Brasil. Assim como, só na TV Brasil, o Brasil todo pode ver ao vivo as festas de São João do Nordeste. Não ocorre na TV pública aquilo que a jornalista Tila Chitunda da TV Pernambuco relatou com propriedade. As emissoras comerciais do eixo Rio-São Paulo, ao transmitirem alguns momentos das festas, dão amplo espaço aos artistas de destaque midiático nacional. Quando entra em cena alguém ou algum grupo conhecido apenas regionalmente ou levando ao público conteúdos menos comerciais, vem o corte para o estúdio ou para os "nossos comerciais"

O jornalismo na TV pública deve igualmente ter outra "pegada". Trata-se igualmente de um "serviço público" e deve contemplar, antes e acima de tudo, a maioria da população. Seu caráter alternativo ao veiculado pelos meios privados apresenta como característica central a busca de informações que atendam necessidades materiais e simbólicas dessa maioria, sem nenhum comprometimento comercial (audiência) ou político partidário.

A construção desse tipo de pauta caracteriza uma forma diferenciada de produzir, editar e veicular notícias. Uma dinâmica que tem como base teórica a ideia de que o jornalismo é uma forma de construção de conhecimento ${ }^{6}$ e deve oferecer um leque amplo de opções ao público ${ }^{7}$. Nesse sentido, a referência informativa deve ser a busca de pautas alternativas às da mídia comercial buscando temas por ela desprezados ou tratados de forma parcial ou distorcida.

Como exemplos dessas pautas podemos citar os avanços obtidos pela economia solidária, a produção agrícola alcançada pelos assentamentos rurais originados das lutas pela reforma agrária, a contextualização da luta pela moradia nos grandes centros urbanos e a própria questão da regulação da mídia, entre tantos outros. A comunicação pública não pode se reduzir a ser apenas mais um microfone, entre tantos outros, colocados à frente de dirigentes empresariais e financeiros. Cabe ainda à comunicação pública realizar a crítica da mídia, papel só a ela possível. Os meios oligopolizados não têm nenhum interesse em realizar publicamente qualquer tipo de autorreflexão crítica.

Não podemos deixar de ressaltar a transformação gradual pela qual passam as formas de ver televisão, com o advento das novas tecnologias. Isso é fundamental para pensarmos políticas e diretrizes culturais para a TV pública. Essas transformações fizeram com que a audiência de fluxos televisivos fosse transformada em audiência de armazenamento. Essa possibilidade de armazenar programas e assisti-los na hora desejada e através de diferentes aparelhos receptores tende a interferir nas grades de programação das emissoras, com o fim até das próprias grades. Dai a necessidade de combinar produtos midiáticos pouco perecíveis com coberturas ao vivo de grandes acontecimentos. A combinação do durável com o imediato será a marca da televisão do futuro. De toda a televisão, comercial ou pública, mas a esta cabe - ainda que no mesmo modelo tecnológico - fazer a diferença pelo conteúdo.

"Numa democracia seria insatisfatório que o público tivesse só uma fonte de informação, entretenimento ou educação através do rádio ou da televisão. Que seja a televisão independente uma efetiva ampliação de escolhas e não de escolhas todas iguais" dizia a lei britânica de televisão já na década de 1960, enfatizando a necessidade da ampliação das alternativas oferecidas ao público.

No Brasil, esse debate foi interditado por três fatores: a hegemonia absoluta do modelo comercial como se fosse o único possível, as restrições impostas pela ditadura (1964-85) ao livre debate e a criação do mito da censura como correspondente a qualquer forma de regulação da mídia no período democrático. Este

\footnotetext{
iv Disponível em: http://tvbrasil.ebc.com.br/sambanagamboa.

v Depoimento dado ao programa VerTV da TV Brasil em junho de 2015. Disponível em: http://tvbrasil.ebc.com.br/vertv/episodio/ a-cobertura-das-festas-juninas.
} 
último contou com a repetição exaustiva de frases como "o melhor controle é o controle remoto", numa tentativa de escamotear o fato de que o seu uso, ao trocar de canais, permite ao público realizar tão somente "escolhas iguais".

Só a televisão pública pode justificar de alguma forma o uso do controle remoto como instrumento de escolha real e diferenciada. Para isso é necessário, no entanto, que a TV pública faça parte de um arcabouço legal democrático independente que incorpore as necessidades, os anseios e as manifestações culturais existentes em toda a sociedade brasileira. Sem excluir a importância de se avivar a imaginação e a criatividade dos profissionais da área, muitos dos quais acham-se impedidos atualmente de dar vazão aos seus talentos, devido aos limites impostos pelo modelo único de comunicação existente no país.

Para tanto não bastam apenas talento e boa vontade. É preciso ação política profunda e constante para fazer da televisão pública um instrumento de emancipação cultural de amplas camadas da sociedade brasileira, hoje confinadas ao consumismo, ao ódio e à brutalidade impostos pela TV comercial.

\section{Referências}

1. Carrato A. Uma história da TV pública brasileira [tese de doutorado]. Brasília, DF: Universidade de Brasília; 2014.

2. Fischer D. O direito de comunicar. São Paulo: Brasiliense; 1984.

3. Leal Filho LL. A televisão pública brasileira, um vazio histórico. Trabalho apresentado ao: Grupo de Trabalho sobre Economia Política e Políticas de Comunicação do XVI Encontro da Compós, UTP, Curitiba, 2007.

4. Broadcasting Research Unit - The Public Service Idea in British Broadcasting-Main Principles. Londres: BBC/British Research Unit; 1986.

5. Blumer JG. Television and the public interest: vulnerable values in european west broadcasting. Londres: Sage; 1992.

6. Faxina E. Do mercado à academia: $\mathrm{O}$ desafio das transformações dos sujeitos discursivos, das institucionalidades e das narrativas jornalísticas na TV pública brasileira [tese de doutorado]. São Leopoldo: Unisinos; 2012.

7. Rothberg D. Jornalismo público. São Paulo: Editora UNESP, 2011.

8. Leal Filho LL. A melhor TV do mundo: o modelo britânico de televisão. São Paulo: Summus Editorial; 1997. 